\title{
Parents' views and experiences of talking about autism with their children
}

Laura Crane ${ }^{1}$, Lydia Jones ${ }^{1}$, Rachel Prosser ${ }^{1}$, Morvarid Taghrizi ${ }^{1}$ and Elizabeth Pellicano $^{2}$

${ }^{1}$ Centre for Research in Autism and Education (CRAE), UCL Institute of Education ${ }^{2}$ Department of Educational Studies, Macquarie University

Correspondence to:

Laura Crane

Centre for Research in Autism and Education (CRAE)

UCL Institute of Education

University College London

London, WC1H 0NU

United Kingdom

Tel: +44(0) 2073315141

Email: L.Crane@ucl.ac.uk

Acknowledgements: We would like to thank the parents that took part in the research, as well as the organisations that assisted with recruitment. 
The way an autism diagnosis is disclosed to parents has been found to play a crucial role in their acceptance of, and the way they cope with, their child's diagnosis. Yet, research into parents' subsequent experiences of disclosing a diagnosis to their children, and talking to their families about autism more generally, is limited. Using an online survey, the current study examined 558 parents' experiences of talking about autism with their autistic and non-autistic children. Most parents $(n=379$, 67.9\%) had told their autistic children about their diagnosis. Despite few parents $(\mathrm{n}=163,20.4 \%)$ receiving advice or support regarding the disclosure of the diagnosis, those that had disclosed felt satisfied with the process $(n=319,84.2 \%)$ and felt confident in talking about autism with their children $(n=339,92.4 \%)$. Those who had not told their autistic children about the diagnosis largely planned to discuss this with their child in the future $(\mathrm{n}=100,73.5 \%)$, felt confident in doing so $(\mathrm{n}=95,70.9 \%)$, and were satisfied with their decision $(n=95,70.4 \%)$. Analysis of open-ended data, using thematic analysis, highlighted the importance of openness and the need to tailor explanations to individual children's needs, whilst acknowledging that disclosure could often be challenging for parents.

Key words: autism, parents, diagnosis, disclosure, awareness, acceptance 


\section{Parents' views and experiences of talking about autism with their children}

Accessing an autism diagnosis can be a lengthy and difficult process, both for parents of autistic ${ }^{1}$ children (Crane, Batty, Adeyinka, Goddard, Henry, \& Hill, 2018; Crane, Chester, Goddard, Henry, \& Hill, 2016; Howlin \& Moore, 1997) and individuals seeking a diagnosis in adulthood (Crane et al., 2018; Jones, Goddard, Hill, Henry, \& Crane, 2014; Lewis, 2017). A key aspect of this process is the disclosure of the diagnosis, with the nature of these consultations influencing how parents view their child's diagnosis and parents' subsequent coping strategies (Hasnat \& Graves, 2000; Reed \& Osborne, 2012). Parents have been shown to value direct, knowledgeable and understanding advice, highlighting the need for clinicians to explain the diagnosis clearly, offer lots of quality information and guidance, and foster open and supportive relationships with them (Abbott, Bernard \& Forge, 2012; Brogan \& Knussen, 2003; Hasnat \& Graves, 2000; Sloper \& Turner, 1993). Less widely researched, however, is the onward process of parents disclosing this diagnosis to their autistic children (Whitaker, 2006), despite parents reporting this to be an area of concern (Mansell \& Morris, 2004).

Research examining the disclosure of potentially sensitive information to children highlights the importance of openness and honesty (e.g., Badarau et al., 2015; Clarke, Davies, Jenney, Glaser, \& Eiser, 2005; Young, Dixon-Woods, Windridge, \& Heney, 2003). Wydra, O'Brien and Merson (2012), for example, reported that when young people were told they were adopted, they were less likely to be satisfied if they felt their parents were withholding information. The need to disclose information as early as possible also appears to be important. Ilioi, Blake,

\footnotetext{
${ }^{1}$ We largely use identity-first (i.e., autistic child), opposed to person- first (i.e., child with autism) language, in view of this being the preferred term of the autistic community (Kenny et al. 2016; Sinclair, 1999) and less associated with stigma (Gernsbacher, 2017).
} 
Jadva, Roman and Golombok (2017) found that children conceived via egg or sperm donation had more positive outcomes the earlier this information was disclosed. Likewise, Last and van Veldhuizen (1996) found that children who were fully informed of their cancer diagnosis at an early stage showed less anxiety and depression than those who received incomplete information.

Despite these recommendations, the difficult nature of such conversations has been acknowledged. Goffman (1968), for example, described how parents of children with intellectual disabilities may choose to withhold their diagnosis from them; forming a 'protective capsule' around their children to ensure they are not aware of their disability. Similarly, research on the disclosure of a cancer diagnosis to children has highlighted concern over causing emotional distress to children and burdening them with information, as well as parents' perceived lack of knowledge or skill in disclosing the information to their children (Badarau at al., 2015). Notwithstanding these concerns, there may be negative consequences to this strategy. These include parents being uncomfortable with deceiving their children (by withholding information from them), as well as broader issues around parents denying their children the opportunity to challenge social stigma surrounding their diagnosis (Todd \& Shearn, 1997).

There has been remarkably little published research examining parents' experiences of talking to their children about their autism diagnosis. In a recent systematic review, Smith, Edelstein, Cox and White (2018) identified just five studies (comprising three published articles and two theses/dissertations) addressing this topic. Two of the studies involved parents (Cadogan, 2015; Finnegan, Trimble \& Egan, 2014), two involved autistic youth (Huws \& Jones, 2008; Mogenson \& Mason, 2015) and one involved both parents and their autistic children (Rossello, 2015); all 
with very limited samples (ranging from nine to 15 participants per study). Together, this research highlighted the reluctance of many parents to disclose an autism diagnosis to their children, with concerns raised that the children would not understand the diagnosis, would experience stigma associated with autism, or might use the diagnosis as an excuse (Smith et al., 2018). Yet positive aspects of the diagnosis were also noted, including greater self-awareness of their strengths and challenges, an enhanced ability for self-advocacy and greater ownership of the diagnosis (Smith et al., 2018).

Given the paucity of existing literature on this topic, the aim of the current research was to examine, on a large-scale, parents' experiences of talking about autism with their children. An online survey was used to address the following four aims: (1) to determine why parents may, or may not, choose to disclose an autism diagnosis to their autistic children; (2) to understand the potential barriers and facilitators to diagnostic disclosure; (3) to examine parents' degree of satisfaction with the help and support offered to them with regards to the disclosure of a diagnosis; and (4) to establish how parents discuss autism more broadly with their autistic (and non-autistic) children (with a focus on topics that were found to be particularly beneficial or challenging to discuss).

\section{Method}

\section{Participants}

An online survey was advertised to primary caregivers (henceforth, 'parents') of children with a formal autism diagnosis, residing in the United Kingdom (UK). A total of 787 parents participated, but 229 cases (29.1\%) were removed during data cleaning: 99 parents $(12.6 \%)$ did not answer any questions; $36(4.6 \%)$ did not indicate if their child knew about their autism diagnosis; nine (1.1\%) were not a parent or 
primary caregiver; $78(9.9 \%)$ reported that their child was currently over the age of 18 years; and seven $(0.9 \%)$ were parents of children who did not have a formal autism diagnosis.

The characteristics of the 558 remaining participants are presented in Table 1. Most respondents were mothers, of a White ethnic background, and spoke English as their first language. The average age of the parents was 41.27 years and they were from a range of geographical regions across the UK. Over half had attended university and almost a fifth were either formally diagnosed or self-identified as autistic.

[insert Table 1 about here]

Most respondents had one child on the autism spectrum. If parents had more than one autistic child, they were asked to respond to the survey regarding their oldest child. The characteristics of the children referred to in the survey are presented in Table 2. These children tended to be male, diagnosed in early childhood, and approximately 10 years of age. Most of the autistic children had additional diagnoses, commonly a physical disability, intellectual disability or mental health condition, as reported by parents. Just over half of the children were reported as having some form of language impairment (mainly difficulties with 'pragmatic' language) yet most children attended mainstream school.

[insert Table 2 about here]

\section{Materials}

A bespoke online questionnaire was developed by a team of autism researchers, drawing on their experience of working with families of children on the autism spectrum. Input was sought from parents of autistic children, who reviewed the survey and offered feedback and advice, based on their personal experiences. The 
questionnaire contained four sections: (1) About you; (2) About your family; (3) About your child on the autism spectrum; and (4) Talking about autism.

Part One - About you. Parents were asked closed questions regarding their age, gender identity, main language spoken, ethnicity, highest educational qualifications, geographic location, and diagnostic status (i.e., if they were autistic themselves) (adapted from Crane et al., 2016).

Part Two - About your family. Parents were asked about the number of children in their household and how many were on the autistic spectrum. They were then asked to detail their relationship to the children on the autism spectrum (i.e., biological parent, adoptive parent, foster parent) (adapted from Crane et al., 2016).

Part Three - About your oldest child on the autistic spectrum. Parents were asked about their children's gender, age (currently and at diagnosis), diagnosis (of autism and, if applicable, other co-occurring conditions), language use, use of communication aids and schooling (adapted from Gotham et al., 2015).

Part Four - Talking about autism. Part Four began by asking parents whether their children knew they were on the autistic spectrum, with three possible response options: 'Yes', 'No', or 'I think so.' Subsequent questions were dependent on the response to this question.

Those responding 'Yes' or 'I think so' were asked closed questions regarding the circumstances in which the diagnosis was disclosed, specifically the children's age at disclosure and who told the children about the diagnosis. Parents were then asked to select if they were satisfied with the way the children's diagnosis was disclosed to them ('Yes', 'Somewhat' or 'No'), if they received any support regarding the diagnostic disclosure ('Yes' or 'No') and, if so, how helpful the support was ('Not at all helpful', 'A little helpful', 'Neutral', 'Somewhat helpful', 'Very helpful'). 
Parents were asked if they thought their children understood their diagnosis ('Yes', 'Somewhat' or 'No'), how often they talked about autism with their children ('Daily', 'Weekly', 'Monthly', 'Yearly', 'Rarely', 'Never') and how satisfied they were with their decision to disclose their children's diagnosis to them ('Very dissatisfied', 'Quite dissatisfied', 'Neither satisfied nor dissatisfied', Quite satisfied', 'Very satisfied'). All the above questions were followed by a free text box, to allow parents to provide further details, if they wished. This section also contained three openended questions, about: (1) the factors that influenced their decision to tell their children about their autism diagnosis; (2) the autism-related topics they discuss with their children; and (3) if any topics were particularly helpful or challenging to discuss.

Parents who responded that their children did not know they were on the autism spectrum were initially asked an open question about the factors that influenced their decision not to tell their children about their autism diagnosis. They were then asked to respond to closed questions about whether they planned to tell their children about their diagnosis in the future ('Yes', 'No', 'Not Sure') and, if so, who they thought would tell their children (e.g., self, family member, school, healthcare professional); and whether they had received any support thus far when making this decision ('Yes' or 'No') and, if so, how helpful this support had been ('Not at all helpful', A little helpful', 'Neutral', 'Somewhat helpful', 'Very helpful'). Parents were then asked to indicate whether they were satisfied with their decision not to tell their children ('Yes', 'Somewhat', 'No'), felt confident in explaining their children's diagnosis to them in the future ('Yes' or 'No'), felt confident explaining what autism means to them ('Yes' or 'No'), and thought their children would understand what receiving an autism diagnosis meant ('Yes', 'Somewhat', 'No'). An 
open-ended text box followed almost all questions in this section, to allow respondents to elaborate on their answers.

At the end of the survey, all parents were asked an open-ended question regarding what advice they would give to other parents of children on the autism spectrum who might be debating if, when and how to discuss autism with their children. They were also asked whether they had any other autistic or non-autistic children and were asked to share their views on talking about autism with them. Finally, they were given the opportunity to elaborate on their answers - to add anything important that they could not discuss elsewhere in the survey.

\section{Procedure}

Ethical approval was obtained via the Department of Psychology and Human Development at UCL Institute of Education. All parents gave informed consent to take part in the survey and participation was anonymous (e.g., names and IP addresses of the participants were not collected).

The research was introduced to participants as a survey on how parents talk about autism with their children. It was emphasized that the survey was open to all parents of children with an autism diagnosis (irrespective of whether their child knew about their diagnosis).

To recruit families, services providing information, support or advice to parents of children on the autism spectrum were identified online and through personal contacts of the research team. All services were emailed, provided with information about the research (including a link to the survey) and were asked to distribute this via their networks. The research was also advertised widely via social media (Facebook and Twitter). The survey was open for eight weeks, between April and June 2017. 


\section{Data analysis}

Quantitative data were presented descriptively (providing total numbers and percentages). Responses to open-ended questions (collected throughout, and at the end of, the survey) were analysed qualitatively, using thematic analysis (Braun \& Clarke 2006). This 'theoretically flexible' approach consisted of several analytical steps that assisted the researchers in the identification of meaningful, consistent themes (Braun \& Clarke, 2006). First, two researchers (LJ and LC) became familiar with the data, through reading and re-reading the data, whilst simultaneously making notes of emerging patterns. Then, extracts of the data were assigned 'codes', which were organised into broader analytical themes. An inductive or 'bottom-up' approach was used to generate the themes, meaning that the themes were generated in response to the data, as opposed to trying to fit the data into pre-defined themes or trying to answer a specific research question; an approach in keeping with the exploratory nature of the work. Themes were identified at a semantic (rather than a latent) level, which meant that the surface meaning of the data was used to generate themes, without making assumptions regarding the wider structures or theories that may have shaped participants' responses. The themes were then reviewed, merging or separating themes as required, and ensuring that there was internal coherence within a theme and strong distinctions between themes. Finally, a negative case series was undertaken, to highlight any data that contradicted the identified themes.

\section{Results}

Quantitative results are presented first, for parents whose children: (1) knew they were on the autistic spectrum; (2) might know they were on the autistic spectrum; and (3) did not know they were on the autistic spectrum. Following this, qualitative results are presented, across all parent respondents. 


\section{Quantitative results}

'Yes'- my child knows they are on the autistic spectrum. As can be seen in Table 3, the majority of parents who participated in this survey had told their child about their autism diagnosis. On average, this was 1.29 years $(S D=2.42$, range $=-6-$ 9 years) after their child received the diagnosis, but sometimes occurred before the formal diagnosis was given. Despite less than $30 \%$ of parents receiving advice or support with the disclosure, most felt confident in taking to their children about the diagnosis and tended to be satisfied with the manner in which the diagnosis was disclosed. Parents spoke about autism with their child frequently (with almost three` quarters of parents discussing autism on a daily or weekly basis), and only a minority of parents thought their children did not understand the diagnosis.

'I Think So' - I think my child knows they are on the autistic spectrum.

Of the 558 respondents, a minority $(n=43 ; 7.7 \%)$ reported that they thought their children knew that they were on the autism spectrum. On average, this was 1.67 years $(S D=2.41$; range $=0-10)$ after the children received their autism diagnosis, and this disclosure tended to be via a family member. Despite few parents receiving advice or support with the disclosure, most were satisfied with the way their children may have found out they were on the autistic spectrum, and felt confident explaining the diagnosis to their children. There was variability regarding the frequency with which this group of parents spoke about autism with their children (ranging from daily to never), and almost three quarters felt their children did not really understand what the diagnosis meant.

'No'- my child does not know they are on the autistic spectrum. 136 of the 558 parents $(24.4 \%)$ reported that their children did not know that they were on the autistic spectrum, but most of these (personally) planned to tell their children about 
their diagnosis in the future. Very few parents (less than 3\%) did not plan to tell their children about their diagnosis, with almost a quarter being unsure. Most parents had not received any advice or support about whether to tell their children about their autism diagnosis, yet felt confident in explaining to their children that they were on the autistic spectrum in the future. Despite this, few parents felt that their children would understand the meaning of the diagnosis. Further analyses showed that this perceived lack of understanding was more common for children with atypical, or little/no spoken, language, $\chi^{2}(4)=9.99, p=.04$, but did not vary depending on the age of the child, $F(2,121)=1.34, p=.26$. This suggests that parents may not disclose their child's diagnosis to them if they felt their language abilities meant that they might not understand the diagnosis, irrespective of their age.

[insert Table 3 about here]

\section{Qualitative results}

We identified three main themes (with associated sub-themes) from the openended data (see Figure 1).

[insert Figure 1 about here]

Theme 1: Being open about the diagnosis. This theme comprised three subthemes: (1) disclosure of diagnosis needs to come early and take place gradually; (2) the child's ownership of the diagnosis; and (3) learning about their diagnosis was perceived to be enlightening and potentially empowering.

Disclosure of diagnosis needs to come early and take place gradually. Many parents who had discussed autism with their children thought it was preferable to introduce the autism diagnosis gradually from a young age: "We didn't want it to be a big thing or event that he would remember - 'the day I was told I had autism' - but a normal everyday part of our family's language." They hoped that this would help 
children assimilate their diagnosis as part of their identity when they were young, as opposed to the diagnosis coming as a "shock" in later life. It was felt that this could help to "normalise" the diagnosis and reinforce the idea that it was nothing to be ashamed of: "we emphasise the 'everyone is different concept' and 'everyone is good at something'." This approach was deemed to be beneficial for the whole family: “our daughter is very understanding of her brother's difficulties because we have included her in all our discussions about autism. This has been a great help in reducing difficulties between them." Yet some parents did prefer to wait until their child was older before disclosing the diagnosis: "at 10 years old, I'm not sure that telling him about his diagnosis is helpful. At 10, all we want to do is 'fit in'. When he is older, he will need to know"; and queried whether this was the right thing to do: "my daughter seems to be happy at the moment, so I prefer not to create anxiety for no reason. I hope I am doing the right thing but it is a tough decision". On reflection, some parents who had first talked to their child about their diagnosis later in life wished it had happened earlier: "I certainly wished we had had that conversation many years earlier. It would have saved our son a lot of bewilderment and anguish.", whilst some felt the opposite: "I kind of wish, in hindsight, that we could have told him when he was a bit older so he would be able to understand it a bit better".

The child's ownership of the diagnosis. Parents emphasized that "you know your child best" so others should "do what feels right for you and your family". Yet a recurring sentiment expressed by parents (particularly those who had informed their child about their diagnosis) was that children had a "right to know" about their diagnosis, and that it was important and inevitable that children be told, as the diagnosis "belongs to them, not me." For many, the obvious time to begin discussions about autism was in response to children's growing self-awareness and 
direct questioning related to the perceived differences between themselves and their peers: "He asked us if he was 'weird' because he knew he was different and he wanted to know why." The same was reported of non-autistic siblings: "if you have other children, as they grow and understand more, they are going to ask questions talking about it makes them aware, understanding and awareness is key for them as they go on in life." Many parents also felt it was important their children heard about the diagnosis from them so they could ensure the information was delivered in a positive manner: "I wanted him to understand autism, to be proud of himself, selfaware of his strengths and weaknesses and be able to talk to others openly and confidently."

\section{Learning about their diagnosis was perceived to be enlightening and}

potentially empowering. There was a sense that telling a child about their diagnosis was empowering and that a child's confidence and self-esteem would improve once they were able to better understand themselves and why they found certain things challenging: "Don't let your child wonder what's wrong with them or be teased and labeled wrongly by other children. Give them the knowledge to understand themselves and build their self-confidence and self-worth. The diagnosis is about them, they own it and should know it." Greater understanding was perceived to be key for non-autistic siblings too: "we told [his sister] about his diagnosis as soon as we got it. It helped her to be understanding and tolerant of his behaviour."

There were several examples of the difficulties, and sometimes subsequent mental health problems, faced by children who knew they were different but did not know why: "She was in a very low state, highly anxious, depressed, angry. She kept saying she was an alien, alone, different. We wanted to be able to help her understand that nothing was wrong with her, she wasn't bad, she simply needed the right 
support." Several parents who were themselves autistic echoed the need for early disclosure, following their own experiences: "As an adult getting a diagnosis now, I wish I had known before. I have spent my life struggling and wishing I could just get on and do things that other people manage easily." This awareness of their diagnosis also allows children to feel part of a wider autistic community, something several respondents remarked on as being hugely beneficial: "I wanted him to understand that his difference had a name and was part of who he was and that there were lots of others like him in the world."

For many families, receiving a diagnosis helped dispel the idea that their children's behaviour was due to them being naughty or disruptive: "My husband and I always thought that she would grow up feeling less isolated and being more selfaware if she understood that there is a reason she finds some things very difficult and that it's not because she is 'naughty', 'lazy' or 'difficult' or any of those other horrible and inaccurate labels our children do often get given." It also allowed their children to better explain their behaviour to others: "We discussed the best way to explain to his friends... and agreed that saying, 'My brain is just wired to think a bit differently'." This type of framing was reported to have positive outcomes for the child: "Helping my son own his diagnosis has enabled him to explain to others when he is feeling slightly out of sorts. He is much better understood now." It was also reported to have positive benefits for non-autistic siblings: "Life has been hard for my two [non-autistic] children as both my autistic children have challenging behaviour and are very intolerant of their siblings. Talking about why they have difficulties and why [the autistic children] can be intolerant at least provides an explanation.”

Yet a few parents did note the challenges associated with the disclosure of a diagnosis, with the aforementioned benefits not being observed for their children. For 
example, some parents reported how their children struggled to accept the diagnosis: "my daughter hates the fact she is autistic and get very upset"; felt "very emotional about [the diagnosis of autism]"; and/or distanced themselves from the diagnosis: "my daughter doesn't like to consider herself as part of the autistic community".

\section{Theme 2: Need to tailor discussions to children's specific needs. This} theme comprised three associated sub-themes: (1) timing and manner of disclosure need to be child-led; (2) celebrating the positives; and (3) embracing everyday opportunities to talk about autism.

Timing and manner of disclosure need to be child-led. Many parents stressed the importance of disclosing a diagnosis when they felt their children were ready: "Parents know best. They can judge if their kid needs to know and how much they need to know. They know if their child would be more content with the info and how much to give." They discussed how this was a personal process and that there was not one approach that would work for all: "Do what you feel is right for your family, tell if you think it will help, hold off if you don't feel your child will understand - every situation needs to be handled differently there is no one-size-fitsall model as so many factors come into play." For example, parents often discussed explaining to their child that their brain was different in some way, even if they did not yet have a full understanding of their diagnosis. This was also true of other family members: "[my daughter] knows her brother has autism but her understanding of this is limited. At the moment, she just sees her brother as her brother... as she gets older and notices differences, then we will talk more and fill in any gaps she has". Respondents felt it important to acknowledge that, whatever approach was taken, all parents were just trying their best to do what was right for their child: "It's an 
individual thing, how you approach it depends on you and your child's circumstances entirely and there is no right or wrong way. We all do our best at the end of the day."

Amongst those who had not told their children of their autism diagnosis, the most common reason was that they felt their children did not have ability to understand what it meant. Nevertheless, they felt it was important to disclose the diagnosis and would do so as and when their children's level of understanding improved: "He's not emotionally aware enough to understand it." A minority of parents made an active decision not to tell their children. In these situations, parents often questioned the utility of telling children about their diagnosis if they were not currently experiencing any difficulties: "My daughter seems to be happy at the moment so I prefer not to create anxiety for no reason. I hope I am doing the right thing but it is a tough decision."

Celebrating the positives. For many parents, it was important to ensure that their children's differences were embraced, particularly with regard to specific strengths linked to their autism: "Focus on the positive, my son has amazing hearing and observes things that constantly amazes me. He takes everything literally and is brilliant at thinking outside the box." Even if children could not see these positives, it was evident parents did: "She says she is crazy, I tell her how special she is." Parents remarked on the need to embrace diversity whenever possible and be mindful of not using negative terminology when talking about autism: "She hates the word 'disorder' so we do not use that." Similarly, respondents highlighted the importance of referring to 'differences' rather than 'deficits': "Explaining that he is like an Apple computer when others are like Microsoft, they can and do work together it's just a different operating system. This helped him to understand how it makes him different to others. He says he's special." Parents reported on the utility of finding autistic role models 
and discussing how their autistic traits had contributed to their success: "Famous people with autism was a positive point. My son had it in his head that he would never be successful but was amazed to see how many successful people are on the spectrum."

Yet caution also needed to be exerted; for example, one parent explained: "I have a slight worry that because of the positive language we have chosen to describe autism, our younger [non-autistic] child may feel less special.” Further, some parents felt that their children were using their autism diagnosis as an excuse for bad behaviour: "he does tend to use his diagnosis to try and get himself out of trouble. It's hard explaining to him that it isn't an excuse for bad behaviour"; "sometimes I now feel he knows too much and uses it for his own gains".

Embracing everyday opportunities to talk about autism. Discussions about autism were frequently described as being dynamic, with particular situations serving as a focal point around which to discuss autism more broadly: "As issues arise, so for example processing, we are able to discuss how her autism affects her and what strategies we can use to make things easier for her." Taking the time to reflect on why things may have been challenging provided opportunities to discuss coping strategies for the future: "Particularly helpful are 'reviews' when a situation hasn't gone well and identifying alternative ways to deal/behave."

Parents reported children often wanted help to try and understand if specific aspects of their behaviour were due to them being autistic: "He mainly asks if the things he does are because of him or autism." They felt that these frequent conversations helped facilitate an open environment where children would hopefully feel comfortable to discuss any concerns they had: "I think it's good to just be open about autism. I think we need to forget the stigma of the past and just discuss all 
aspects of autism as you would any other condition. We do this in our household so that she doesn't feel she should ever be ashamed of her diagnosis." Some parents were waiting for their child to begin initiating such conversations: "when he starts to question why he does things differently from his siblings and friends then that is the time to explain everything to him".

Theme 3: Challenges parents faced when talking about autism. This theme comprised two subthemes: (1) Need for additional professional support; and (2) Concern that disclosure may have a detrimental effect.

Need for additional professional support. On several occasions, parents reported that they lacked confidence in their ability to explain their children's diagnosis to them, for example: "It's difficult to explain autism to a child and to find the right words"; and "I'm not qualified to explain to a child about a condition I'm still learning about." Parents often felt that more support from professionals was required to ensure disclosure was done 'well': "We would've liked professional advice to have been available about how to tell our son about his condition.” Specifically, respondents wanted help ensuring disclosure was done in a positive manner and was delivered in such a way their children would be able to understand: "Parents need to be able to access information before they do it. Not in academic, jargon-full language, but in a child-friendly language that is accessible in different formats and is engaging." Some parents felt that support should come from "join[ing] a support group and get[ting] advice from other parents not professionals."

Concern that disclosure may have a detrimental effect. For some parents, it proved difficult to decide if it was in their children's best interests to tell them of their autism diagnosis. Commonly expressed worries were that a 'label' would lead to their child experiencing stigma or bullying from peers: "I worry that if he is told too 
young, that he will tell this information to other children who may use that information to further isolate him as 'different'." Some parents were also cautious in case their child felt "defined by a condition", with one parent noting: "I'm not sure if I did the right thing in telling them. She feels this label's her and sets her apart from others and that if people hear she has a diagnosis they will have preconceived ideas about her." However, some parents actively challenged such notions, whether held by people they knew or the children themselves, rebuking suggestions that autism could be used as "a justification for bad behaviour" or "an excuse, or a reason for not achieving. We celebrate it and help him see that without it he wouldn't be himself."

Parents were sometimes concerned that the disclosure of the diagnosis may be anxiety provoking for their children: "I think she would be scared and her level of anxiety would increase. My daughter only wants to blend with the others and does not want to feel different." There were also fears disclosure could exacerbate pre-existing mental health issues: "My son has low self-esteem and a lot of anxiety on a daily basis, if I don't tell him in the right way I may add to this." Indeed, in some instances it did seem that children found their diagnosis difficult to accept, either simply being reluctant to discuss matters related to autism or feeling frustrated at being autistic: "He is very resistant to the idea of being different, he considers it quite rightly to be unfair and gets upset by any discussion of it."

Some parents also found it very difficult to engage in discussions about autism with their non-autistic children, and discussed the difficulties this raised: "My other daughters can be very understanding about my daughter's diagnosis and at other times they resent that she is sometimes treated differently...it has a big impact on our family". Parents were often worried about different rules being applied to the autistic and non-autistic children in the family: "trying to explain why their sibling hits out at 
them and cannot be reprimanded properly for it is hard. Explaining why he is always shouting and getting angry. And explaining why we cannot go to certain places because of his behaviour is clearly depressing to my other child."; and felt this "puts an awful lot of pressure on a family." This was reported to be particularly difficult when the non-autistic children did not want to talk about autism: "She knows her brother is autistic but doesn't like to talk about it too much - in some ways she's jealous he seems to get so much attention and his autism is why."

In the vast majority of cases, however, parental initial concerns were unfounded, with children being more accepting of their diagnosis than parents had anticipated: "He is now very proud of himself and wouldn't take away the autism if he had the choice." Parents were often impressed with the resilience of their children: "our kids are much stronger than we think and can usually handle knowing about their autism"; and generally did not regret their decision to disclose: "I'm really glad I did. My children see autism as part of life and are completely accepting of it."

There was often a sense of relief in being able to give a name to something they had been struggling with: "the relief my son felt when I shared my suspicions still can bring me to tears." This, in turn, allowed families to begin finding ways to address these challenges: "Telling him about his diagnosis has lifted a weight off us all in that now there is an explanation for all of the things he does and there are things we can now do to help." This was also thought to be true of non-autistic siblings: "be honest and reinforce what a good job they are doing as a sibling. Find a simple analogy that helps and keep referring back to it. Explain your decisions."

\section{Discussion}

Not all parents are able to communicate verbally with their children about their autism diagnoses, for example, due to their children's severe communicative 
challenges and/or the presence of profound intellectual disabilities. While it is important to ensure that this subset of the autistic population is not overlooked (see Stedman, Taylor, Erard, Peura \& Siegel, 2018), it is essential that families of autistic children who can learn about their diagnosis feel confident and supported in talking about autism with their children. The first step towards achieving this is to examine the experiences of parents who have been through this process of disclosure and discussion. Despite few parents receiving advice or support regarding the disclosure of the diagnosis, most parents who participated in this study had told their autistic children about their diagnosis, were satisfied with the process of disclosure, and felt confident in talking about autism with their children. Likewise, those who had not yet told their child about the diagnosis largely planned to discuss this with their child in the future, felt confident in doing so and were satisfied with their decision. Parents highlighted the importance of openness and the need to tailor explanations to individual children, whilst acknowledging that disclosure was often a challenging decision.

Parents in the current study highlighted the importance of being open and honest with children about their autism diagnosis, yet they also wanted to be in control of the way the diagnosis was disclosed (see also Finnegan et al., 2014). Specifically, they mentioned the importance of information being introduced by parents, given gradually, and framed positively. This latter point is key, since young autistic people are often keen to distance themselves from their diagnosis, and feel shame that they are 'not normal' (Ruiz Calzada, Pistrang, \& Mandy, 2012). Research examining how autistic adults respond to their diagnosis has highlighted the importance of celebrating differences and unique traits in order to develop a positive autistic self-identity (Brownlow \& O’Dell, 2006; Mogensen \& Mason, 2015). The 
development of evidence-based psychoeducation programmes (e.g., Gordon et al., 2015) that help young autistic people understand more about autism, gain an insight into the strengths and potential weaknesses that their autism diagnosis brings, and enhance their self-awareness, may be particularly useful in mitigating these negative self-perceptions.

With regard to precisely when discussions about autism should first be broached, there was a sense that this was a very individual process. This individual nature accords with research on how autistic adults diagnosed in childhood talk about their diagnosis, with perspectives varying from ambivalence to acceptance to fully embracing an autistic identity (see Cribb, Kenny \& Pellicano, in press). Many parents in the current study felt that it was best to tell the child at the earliest opportunity, as soon as they were perceived to have the capacity to understand their diagnosis, in the hope that this would allow their autism to become a part of their identity from the beginning. Indeed, Huws and Jones (2008) found that some autistic adults experienced "shock, disappointment and disbelief" (p. 104) on finding out that they were autistic, with these negative emotions being more pronounced in those whose parents delayed informing them of their diagnosis. This is also supported by accounts from autistic adults stating they wish they had been told of their diagnosis earlier in life (e.g., Jones 2001; Jones et al., 2014), as well as the responses of autistic parents who responded to the current survey (who emphasised the importance of initiating these discussions as early as possible).

Despite these clear benefits to disclosure and openly talking about autism, many parents still found it challenging. Although the utility of a diagnostic label was mentioned, parents were concerned it had (or potentially could have) a negative impact; with some being worried that their child would become defined by their 
diagnosis or that "the label becomes more significant than the child" (Hodge, 2005, p. 2). Others expressed concerns about stigma or discrimination if others knew about their diagnosis, as also reported in other research (e.g., Gray, 2002; Huws \& Jones, 2008; Ruiz Caldaza et al., 2012; Smith et al., 2018). Mogensen and Mason (2015) highlighted how a diagnostic label can be both helpful at a personal level (e.g., in helping an individual better understand their behaviour) whilst simultaneously feeling oppressive due to the stigma associated with autism. Such negative reactions do not suggest these discussions should not be had - rather that parents need more support to initiate them. As the most stressful time in the diagnostic process is shortly after diagnosis (Rivard, Terroux, Parent-Boursier \& Mercier, 2014), the need for parents to decide how best to inform their child of their diagnosis can create additional worry during an already difficult period. Despite these issues, the majority of parents who had disclosed the diagnosis to their child were pleased to have done so.

In summary, this research brought together the voices of hundreds of parents to understand how families talk about autism. It is not, however, without its limitations. The first relates to sampling characteristics. Despite the relatively large sample size (especially compared to previous research, see Smith et al., 2018), the parents predominantly had children with sufficient language ability to be able to talk about autism. The survey also tended to be completed by mothers. Fathers are commonly underrepresented in research regarding the parenting of autistic children (Johnson \& Simpson, 2013), yet mothers and fathers of autistic children have been shown to have different parenting styles and coping mechanisms (Gau et al., 2010; Gray, 2003). Parents were recruited largely through social groups, and it is likely that parents who engage in such groups are more likely to have accepted their child's diagnosis (and therefore view it in a more positive manner) which may have affected 
the results. The current study also largely comprised parents from a White ethnic background, who were fairly well educated (with over half being educated to university level). Such families may experience different routes to accessing an autism diagnosis, and different reactions to their child's autism diagnosis (e.g., Hussein, Pellicano \& Crane, 2018; Kelly et al., 2017). Consequently, their experiences of disclosing their child's autism diagnosis to them might be very different and investigation would likely require bespoke investigations involving the communities as co-producers of such research (e.g., Fox, Aabe, Turner, Redwood, \& Rai, 2017; Selman, Fox, Aabe, Turner, Rai, \& Redwood, 2017).

The second limitation relates to our focus on parents' perspectives - rather than on the views and experiences of the children themselves, which may not mirror those of their parents. Future research should adopt a multi-informant approach involving parents, siblings and the children themselves - to understand these issues more fully. Ruiz Calzada et al. (2012) noted several instances where the benefits of a diagnosis perceived by the parents did not translate to benefits experienced by the child. An important place for parents to turn for advice and guidance on a range of issues affecting their child is the wider autistic community, so gathering their opinions on this topic in a systematic way is vital.

To conclude, the current study generated a rich data set of both quantitative and qualitative data on how parents talk about autism with their children. Future work should utilise these results to produce professional guidance on talking about autism that specifically addresses the parental concerns identified here, including, for example, advice on how to determine when might be best to broach the subject and how to give information in a developmentally-sensitive manner. Whilst we did endeavour to be as inclusive as possible in terms of who could participate in this 
research (and, indeed, many parents did take part who explained that their children did not have the intellectual/language abilities to comprehend a diagnosis), it is possible that different guidelines/explanations are needed for autistic children with additional intellectual disabilities and/or language delays. It will be crucial to explore this in future work. 


\section{References}

Abbott, M., Bernard, P., \& Forge, J. (2012). Communicating a diagnosis of Autism Spectrum Disorder- a qualitative study of parents' experiences. Clinical Child Psychology and Psychiatry, 18(3), 370-382. doi: $10.1177 / 1359104512455813$

Badarau, D., Wangmo, T., Ruhe, K., Miron, I., Colita, A., Dragomir, M., Schildmann, J., \& Elger, B. (2015). Parents' Challenges and Physicians' Tasks in Disclosing Cancer to Children. A Qualitative Interview Study and Reflections on Professional Duties in Pediatric Oncology. Pediatric Blood \& Cancer, 62(12), 2177-2182. doi: 10.1002/pbc.25680

Braun, V., \& Clarke, V. (2006). Using Thematic Analysis in Psychology. Qualitative Research in Psychology, 3(2), 77-101. doi: 10.1191/1478088706qp063oa

Brogan, C., \& Knussen, C. (2003). The disclosure of a diagnosis of an autistic spectrum disorder. Autism, 7, 31-46. doi: 10.1177/1362361303007001004

Brownlow, C., \& O’Dell, L. (2006). Constructing an autistic identity: AS voices online. Mental Retardation, 44(5), 315-321. doi: 10.1352/00476765(2006)44[315:CAAIAV]2.0.CO;2

Cadogan, S. (2015). Parent reported impacts of their disclosure of their child's asd diagnosis to their children. University of Calgary. Retrieved from http://theses.ucalgary.ca/bitstream/11023/2298/4/ucalgary_2015_cadogan_sa rah.pdf (2 August 2018)

Clarke, S. A., Davies, H., Jenney, M., Glaser, A., \& Eiser, C. (2005). Parental communication and children's behaviour following diagnosis of childhood leukaemia. Psycho-Oncology, 14(4), 274-281. doi: 10.1002/pon.843 
Crane, L., Batty, R., Adeyinka, H., Goddard, L., Henry, L.A., \& Hill, E.L. (2018). Autism diagnosis in the United Kingdom: Perspectives of autistic adults, parents and professionals. Journal of Autism and Developmental Disorders. doi: 10.1007/s10803-018-3639-1

Crane, L., Chester, J. W., Goddard, L., Henry, L. A., \& Hill, E. (2016). Experiences of autism diagnosis: A survey of over 1000 parents in the United Kingdom. Autism, 20(2), 153-162. doi: 10.1177/1362361315573636

Cribb, S., Kenny, L., \& Pellicano, E. (in press). "I definitely feel more in control of my life": The perspectives of young autistic people and their parents on emerging adulthood. Autism.

Finnegan, R., Trimble, T., \& Egan, J. (2014). Irish parents' lived experience of learning about and adapting to their child's autistic spectrum disorder diagnosis and their process of telling their child about their diagnosis. The Irish Journal of Psychology, 35(3), 78-90. doi: $10.1080 / 03033910.2014 .982143$

Fox, F., Aabe, N., Turner, K., Redwood, S., \& Rai, D. (2016). "It was like walking without knowing where I was going" A qualitative study of Autism in a UK Somali Migrant Community. Journal Autism Developmental Disorders, 47(2), 305- 315. doi: 10.1007/s10803-016-2952-9

Gau, S. S. F., Chou, M., Lee, J., Wong, C., Chou, W., Chen, M., Soong, W., \& Wu, Y. (2010). Behavior problems and parenting styles among Taiwanese children with autism and their siblings. Psychiatry and Clinical Neuroscience, 64, 7078. doi: 10.1111/j.1440-1819.2009.02034.x 
Gernsbacher, M.A. (2017). The use of person-first language in scholarly writing may accentuate sigma. Journal of Child Psychology and Psychiatry, 58(7), 859861. doi: 10.1111/jcpp.12706

Goffman, E. (1968). Stigma: Notes on the Management of Spoiled Identity. Middlesex, UK: Harmondsworth Press.

Gordon, K., Murin, M., Baykaner, O., Roughan, L., Livermore-Hardy, V., Skuse, D., \& Mandy, W.P.L. (2015). A randomised controlled trial of PEGASUS, a psychoeducational programme for young people with high-functioning autism spectrum disorder. Journal of Child Psychology and Psychiatry, 56(4), 468-476. doi: 10.1111/jcpp.12304

Gotham, K., Marvin, A.R., Lounds Taylor, J., Warren, Z., Anderson, C.M., Law, P.A., Law, J.K., \& Lipkin, P.H. (2015). Characterizing the daily life, needs, and priorities of adults with autism spectrum disorder from the Interactive Autism Network data. Autism, 19(7), 794-804. doi: 10.1177/1362361315583818

Gray, D. E. (2002). 'Everybody just freezes. Everybody is just embarrassed': Felt and enacted stigma among parents of children with high functioning autism. Sociology of Health and Illness, 24(6), 734-749. doi: 10.1111/14679566.00316

Gray, D. E. (2003). Gender and coping: The parents of children with high functioning autism. Social Science and Medicine, 56, 631-664. doi: 10.1016/S02779536(02)00059-X

Hasnat, M., \& Graves, P. (2000). Disclosure of developmental disability: A study of parent satisfaction and the determinants of satisfaction. Journal of Paediatrics and Child Health, 36, 32-35. doi: 10.1046/j.14401754.2000.00463 
Hodge, N. (2005) Reflections on diagnosing autism spectrum disorders. Disability \& Society, 20(3), 345-349. doi: 10.1080/09687590500060810

Howlin, P., Moore, A. (1997). Diagnosis in autism: a survey of over 1200 patients in the UK. Autism, 1(2), 135-162. doi: 10.1177/1362361397012003

Hussein, A.M., Pellicano, E., \& Crane, L. (2018). Understanding Somali parents' knowledge and awareness of autism. Autism. doi:

$10.1177 / 1362361318813996$

Huws, J. C., \& Jones, R. S. (2008). Diagnosis, disclosure, and having autism: An interpretative phenomenological analysis of the perceptions of young people with autism. Journal of Intellectual and Developmental Disability, 33(2), 99107. doi: $10.1080 / 13668250802010394$

Ilioi, E., Blake, L., Jadva, V., Roman, G., \& Golombok, S. (2017). The role of age of disclosure of biological origins in the psychological wellbeing of adolescents conceived by reproductive donation: a longitudinal study from age 1 to age 14. Journal of Child Psychology and Psychiatry, 58(3), 315-324. doi: $10.1111 /$ jcpp. 12667

Johnson, N. L., \& Simpson, P. M. (2013). Lack of father involvement in research on children with autism spectrum disorder: maternal parenting stress and family functioning. Issues in Mental Health Nursing, 34(4), 220-228. doi: $10.3109 / 01612840.2012 .745177$

Jones, G. (2001). Giving the diagnosis to the young person with Asperger Syndrome or high functioning autism. Good Autism Practice, 2(2), 65-73.

Jones, L., Goddard, L., Hill, E. L., Henry, L. A., \& Crane, L. (2014). Experiences of receiving a diagnosis of autism spectrum disorder: A survey of adults in the United Kingdom. Journal of Autism and Developmental Disorders, 44(12), 
3033-3044. doi: 10.1007/s10803-014-2161-3

Kelly, B., Williams, S., Collins, S., Mushtaq, F., Mon-Williams, M., Wright, B., Mason, D., \& Wright, J. (2017). The association between socioeconomic status and autism diagnosis in the United Kingdom for children aged 5-8 years of age: Findings from the Born in Bradford cohort. doi:

$10.1177 / 1362361317733182$

Kenny, L., Hattersley, C., Molins, B., Buckley, C., Povey, C., \& Pellicano, E. (2016). Which terms should be used to describe autism? Perspectives from the UK autism community. Autism, 20(4), 442-462. doi: 10.1177/1362361315588200

Last, B. F., \& Van Veldhuizen, A. M. H. (1996). Information about diagnosis and prognosis related to anxiety and depression in children with cancer aged 8-16 years. European Journal of Cancer, 32, 290-294. doi: 10.1016/09598049(95)00576-5

Lewis, L. F. (2017). A Mixed Methods Study of Barriers to Formal Diagnosis of Autism Spectrum Disorder in Adults. Journal of Autism and Developmental Disorders, 47(8), 2410-2424. doi: 10.1007/s10803-017-3168-3

Mansell, W., \& Morris, K. (2004). A survey of parents' reactions to the diagnosis of an autistic spectrum disorder by a local service: Access to information and use of services. Autism, 8(4), 387-407. doi: 10.1177/1362361304045213

Morgensen, L., \& Mason, J. (2015). The meaning of a label for teenagers negotiating identity: experiences with autism spectrum disorder. Sociology of Health and Illness, 37(2), 255-269. http://dx.doi.org/10.1111/1467-9566.12208

Reed, P., \& Osborne, L. A. (2012). Diagnostic practice and it's impacts on parental health and child behaviour problems in autism spectrum disorders. Archives 
of Disease in Childhood, 97, 927-931. doi: 10.1136/archdischild-2012301761

Rivard, M., Terroux, A., Parent-Boursier, C., \& Mercier, C. (2014). Determinants of Stress in Parents of Children with Autism Spectrum Disorders. Journal of Autism and Developmental Disorders, 44(7), 1609-1620. doi: $10.1007 / \mathrm{s} 10803-013-2028-\mathrm{Z}$

Rossello, E. (2015). “I have what?” A phenomenological inquiry into disclosing a diagnosis of Asperger's disorder to adolescents. Doctoral dissertation, Chicago School of Professional Psychology.

Ruiz Calzada, R., Pistrang, N., \& Mandy, W. P. (2012). High-functioning autism and Asperger's disorder: utility and meaning for families. Journal of Autism and Developmental Disorders, 42(4), 230-243. doi: 10.1007/s10803-011-1238-5

Selman, L., Fox, F., Aabe, N., Turner, K., Rai, D., \& Redwood, S. (2017). 'You are labelled by your children's disability': A community-based, participatory study of stigma among Somali parents of children with autism living in the United Kingdom. Ethnicity and Health. doi: $10.1080 / 13557858.2017 .1294663$.

Sinclair, J. (1999). Why I dislike 'person-first' language. Retrieved from: http://web.archive.org/web/20090210190652/http://web.syr.edu/ jisincla/pers on_first.htm (accessed 21 January 2018)

Sloper, E., \& Turner, S. (1993). Determinants of Parental Satisfaction with Disclosure of Disability. Developmental medicine and Child Neurology, 29, 139-152. doi: 10.1111/j.1469-8749.1993.tb11733.x

Smith, I.C., Edelstein, J.A., Cox, J.E., \& White, S.W. (2018). Parental Disclosure of ASD Diagnosis to the Child: A Systematic Review. Evidence Based Practice 
in Child and Adolescent Mental Health, 3(2), 98-105. doi:

$10.1080 / 23794925.2018 .1435319$

Stedman, A., Taylor, B., Erard, M., Peura, C., \& Siegel, M. (2018). Are Children Severely Affected by Autism Spectrum Disorder Underrepresented in Treatment Studies? An Analysis of Literature. Journal of Autism and Developmental Disorders. doi: 10.1007/s10803-018-3844-y

Todd, S., \& Shearn, J. (1997). Family dilemmas and secrets: Parents' disclosure of information to their adult offspring with learning disabilities. Disability and Society, 12, 341-366. doi: 10.1080/09687599727218

Whitaker, P. (2006).”'Why's it all so difficult?" Sharing the Diagnosis with the Young Person.' In D Murray (ed.) Coming out Asperger: Diagnosis, Disclosure and Self-Confidence. London, UK: Jessica Kingsley Publishers.

Wydra, M., O'Brien, K. M., \& Merson, E. S. (2012). In Their Own Words: Adopted Persons' Experiences of Adoption Disclosure and Discussion in Their Families. Journal of Family Social Work, 15, 62-77. doi: $10.1080 / 10522158.2012 .642616$

Young, B., Dixon-Woods, M., Windridge, K. C., Heney, D. (2003). Managing communication with young people who have a potentially life threatening chronic illness: Qualitative study of patients and parents. BMJ, 326, 305-308. doi: $10.1136 / \mathrm{bmj} .326 .7384 .305$ 
Table 1.

Parent Characteristics $(n=558)$.

\begin{tabular}{|c|c|c|}
\hline & haracteristic & $n(\%)$ \\
\hline \multirow[t]{3}{*}{ Gender } & Male & $24(4.3)$ \\
\hline & Female & $533(95.5)$ \\
\hline & Prefer not to say & $1(0.2)$ \\
\hline \multirow[t]{2}{*}{ Age, $n=553$} & Mean: years (SD) & $41.27(6.56)$ \\
\hline & Range: years & $24-60$ \\
\hline \multirow{6}{*}{ Ethnicity } & White & $541(97.0)$ \\
\hline & Black or Black British Caribbean & $2(0.4)$ \\
\hline & Asian or Asian British & $3(0.5)$ \\
\hline & Mixed & $5(0.9)$ \\
\hline & Chinese or any other ethnic group & $1(0.2)$ \\
\hline & Prefer not to say & $4(0.7)$ \\
\hline \multirow[t]{12}{*}{ Location } & East of England & $50(9.0)$ \\
\hline & East Midlands & $8(1.4)$ \\
\hline & London & $49(8.8)$ \\
\hline & North East & $38(6.8)$ \\
\hline & North West & $16(2.9)$ \\
\hline & Northern Ireland & $207(37.1)$ \\
\hline & Scotland & $21(3.8)$ \\
\hline & South East & $64(11.5)$ \\
\hline & South West & $63(11.3)$ \\
\hline & Wales & $2(0.4)$ \\
\hline & West Midlands & $15(2.7)$ \\
\hline & Yorkshire and the Humber & $25(4.5)$ \\
\hline \multirow[t]{2}{*}{ First Language } & English & $539(96.6)$ \\
\hline & Other & $19(3.4)$ \\
\hline Highest Educational & GCSEs (14-16 years) & $94(16.8)$ \\
\hline \multirow[t]{6}{*}{ Qualification } & National Vocational Qualifications & $53(9.5)$ \\
\hline & A/AS Levels (16-18 years) & $83(14.9)$ \\
\hline & First Degree (e.g. BA, BSc) & $192(34.4)$ \\
\hline & $\begin{array}{l}\text { Higher Degree (e.g. PGDip, MA, } \\
\text { MSc, } \mathrm{PhD} \text { ) }\end{array}$ & $110(19.7)$ \\
\hline & I do not have any qualifications & $10(1.8)$ \\
\hline & Other & $16(2.9)$ \\
\hline \multirow[t]{4}{*}{ Autism Diagnosis? } & No & $451(80.8)$ \\
\hline & Believe so but no diagnosis & $83(14.9)$ \\
\hline & In process of obtaining a diagnosis & $9(1.6)$ \\
\hline & Have a clinical diagnosis & $15(2.7)$ \\
\hline \multirow[t]{2}{*}{ Children in Household } & Mean: number (SD) & $2.17(0.87)$ \\
\hline & Range: number & $1-6$ \\
\hline
\end{tabular}




\begin{tabular}{llc} 
Children on the & One & $446(79.9)$ \\
Autism Spectrum & Two & $101(18.1)$ \\
& Three & $11(2.0)$ \\
& & $552(98.9)$ \\
Relation to & Biological Parent & $4(0.7)$ \\
Child/Children on the & Adoptive Parent & $2(0.4)$ \\
\hline Autism Spectrum & Foster Parent & \\
\hline
\end{tabular}


Table 2.

Characteristics of oldest child on the Autism Spectrum, $n=636$

\begin{tabular}{|c|c|c|}
\hline & Characteristic & $n(\%)$ \\
\hline \multirow{3}{*}{ Gender } & Male & $417(74.7)$ \\
\hline & Female & $135(24.2)$ \\
\hline & Prefer not to say & $6(1.1)$ \\
\hline \multirow{2}{*}{$\begin{array}{l}\text { Age at Diagnosis } \\
(n=506)\end{array}$} & Mean: years (SD) & $6.46(3.23)$ \\
\hline & Range: years & $2-17$ \\
\hline \multirow{2}{*}{$\begin{array}{l}\text { Age at time of Study } \\
(n=525)\end{array}$} & Mean: years (SD) & $10.12(3.52)$ \\
\hline & Range: years & $2-17$ \\
\hline \multirow[t]{8}{*}{ Diagnosis } & Autism & $113(20.3)$ \\
\hline & Autism Spectrum & $231(41.4)$ \\
\hline & Disorder/Condition & \\
\hline & Asperger's Syndrome/Disorder & $149(26.7)$ \\
\hline & High-Functioning Autism & $60(10.8)$ \\
\hline & Pervasive Developmental Disorder- & $2(0.4)$ \\
\hline & Not Otherwise Specified & \\
\hline & Other & $3(0.5)$ \\
\hline \multirow[t]{13}{*}{ Location of Diagnosis } & East of England & $46(8.2)$ \\
\hline & East Midlands & $6(1.1)$ \\
\hline & London & $58(10.4)$ \\
\hline & North East & $37(6.6)$ \\
\hline & North West & $17(3.0)$ \\
\hline & Northern Ireland & $206(36.9)$ \\
\hline & Scotland & $21(3.8)$ \\
\hline & South East & $61(10.9)$ \\
\hline & South West & $63(11.3)$ \\
\hline & Wales & $2(0.4)$ \\
\hline & West Midlands & $16(2.9)$ \\
\hline & Yorkshire and the Humber & $22(3.9)$ \\
\hline & Other & $3(0.5)$ \\
\hline \multirow[t]{7}{*}{ Other Diagnoses } & None & $261(46.8)$ \\
\hline & Physical Disability & $33(5.9)$ \\
\hline & Intellectual Disability & $107(19.2)$ \\
\hline & $\begin{array}{l}\text { Other Neurodevelopmental } \\
\text { Condition }\end{array}$ & $99(17.7)$ \\
\hline & Mental Health Condition & $93(30.7)$ \\
\hline & Genetic Condition & $9(1.6)$ \\
\hline & Other & $114(20.4)$ \\
\hline Use of Spoken & Completely typical & $244(43.7)$ \\
\hline \multirow[t]{2}{*}{ Language } & $\begin{array}{l}\text { Difficulties, mainly with pragmatic } \\
\text { language }\end{array}$ & $270(48.4)$ \\
\hline & Little or no spoken language & $44(7.9)$ \\
\hline
\end{tabular}


Communication Aids Sign Language

$25(4.5)$

High-Tech Assistive Technology

$8(1.4)$

Low-Tech Assistive Technology

$67(12.0)$

Communication by

$191(34.2)$

gesture/behaviour

Education

Mainstream School

$426(76.3)$

Specialist Unit/Base within

$33(5.9)$

mainstream School

Specialist School

$71(12.7)$

Home School

$13(2.3)$

Other

$2(0.4)$

N/A

$13(2.3)$ 
Table 3.

Quantitative data on diagnostic disclosure for children whose parents responded Yes (their child was aware of their diagnosis), I think so (they think their child was aware of their diagnosis) and No (their child was not aware of their diagnosis)

\begin{tabular}{|c|c|c|c|c|}
\hline & & $\begin{array}{l}\text { Yes } \\
(n=379 \\
67.9 \%)\end{array}$ & $\begin{array}{l}\text { I think so } \\
(n=43 \\
7.7 \%)\end{array}$ & $\begin{array}{l}\text { No } \\
(n=136, \\
24.4 \%)\end{array}$ \\
\hline $\begin{array}{l}\text { Age (years) child } \\
\text { found out they } \\
\text { were on the } \\
\text { autistic spectrum }\end{array}$ & & $\begin{array}{l}8.59(\mathrm{SD}= \\
2.74, \text { range } \\
=2-17)\end{array}$ & $\begin{array}{l}7.62(\mathrm{SD}= \\
3.23, \text { range } \\
2-15)\end{array}$ & $\mathrm{n} / \mathrm{a}$ \\
\hline $\begin{array}{l}\text { The person who } \\
\text { informed (or was } \\
\text { going to inform) } \\
\text { the child of the } \\
\text { diagnosis }\end{array}$ & $\begin{array}{l}\text { Parent } \\
\text { Another family } \\
\text { member } \\
\text { Child's school } \\
\text { Healthcare } \\
\text { professional } \\
\text { Other }\end{array}$ & $\begin{array}{l}332(87.6 \%) \\
7(1.8 \%) \\
12(3.2 \%) \\
50(13.2 \%) \\
0\end{array}$ & $\begin{array}{l}0 \\
29(67.4 \%) \\
4(9.3 \%) \\
2(4.7 \%) \\
8(18.6 \%)\end{array}$ & $\begin{array}{l}97(97.0 \%) \\
3(3.0 \%) \\
1(1.0 \%) \\
1(1.0 \%) \\
0\end{array}$ \\
\hline $\begin{array}{l}\text { Satisfaction with } \\
\text { the manner in } \\
\text { which their child } \\
\text { found out about } \\
\text { their diagnosis }\end{array}$ & $\begin{array}{l}\text { Yes } \\
\text { Somewhat } \\
\text { No }\end{array}$ & $\begin{array}{l}319(84.2 \%) \\
40(10.6 \%) \\
17(4.5 \%)\end{array}$ & $\begin{array}{l}21(50.0 \%) \\
12(28.6 \%) \\
9(21.4 \%)\end{array}$ & $\begin{array}{l}\mathrm{n} / \mathrm{a} \\
\mathrm{n} / \mathrm{a} \\
\mathrm{n} / \mathrm{a}\end{array}$ \\
\hline $\begin{array}{l}\text { Whether advice } \\
\text { or support was } \\
\text { received } \\
\text { regarding the } \\
\text { disclosure }\end{array}$ & $\begin{array}{l}\text { Yes } \\
\text { No }\end{array}$ & $\begin{array}{l}109(28.8 \%) \\
267(70.4 \%)\end{array}$ & $8(19.0 \%)$ & $\begin{array}{l}17(12.6 \%) \\
118(87.4 \%)\end{array}$ \\
\hline $\begin{array}{l}\text { How helpful this } \\
\text { support was }\end{array}$ & $\begin{array}{l}\text { Very/somewhat } \\
\text { helpful } \\
\text { Neutral } \\
\text { A little/not at all } \\
\text { helpful }\end{array}$ & $\begin{array}{l}92(84.4 \%) \\
7(6.4 \%) \\
9(8.2 \%)\end{array}$ & $\begin{array}{l}6(75 \%) \\
2(25 \%)\end{array}$ & $\begin{array}{l}9(52.9 \%) \\
4(23.5 \%) \\
4(23.5 \%)\end{array}$ \\
\hline $\begin{array}{l}\text { Whether parent is } \\
\text { confident in } \\
\text { explaining the } \\
\text { diagnosis of } \\
\text { autism to their } \\
\text { child (now or in } \\
\text { future) }\end{array}$ & $\begin{array}{l}\text { Yes } \\
\text { Somewhat } \\
\text { No }\end{array}$ & $\begin{array}{l}230(62.7 \%) \\
109(29.7 \%) \\
28(7.6 \%)\end{array}$ & $\begin{array}{l}18(42.9 \%) \\
15(35.7 \%) \\
9(21.4 \%)\end{array}$ & $95(70.9 \%)$ \\
\hline $\begin{array}{l}\text { Whether child } \\
\text { understands (or } \\
\text { would } \\
\text { understand) what }\end{array}$ & $\begin{array}{l}\text { Yes } \\
\text { Somewhat } \\
\text { No }\end{array}$ & $\begin{array}{l}97(26.4 \%) \\
218(59.4 \%) \\
52(14.2 \%)\end{array}$ & $31(73.8 \%)$ & $\begin{array}{l}11(8.2 \%) \\
48(35.8 \%) \\
75(56.0 \%)\end{array}$ \\
\hline
\end{tabular}




\begin{tabular}{|c|c|c|c|c|}
\hline How often the & Daily & $92(25.5 \%)$ & $5(12.8 \%)$ & $\mathrm{n} / \mathrm{a}$ \\
\hline parent talks about & Weekly & $162(44.9 \%)$ & $9(23.1 \%)$ & $\mathrm{n} / \mathrm{a}$ \\
\hline autism with their & Monthly & $49(13.6 \%)$ & $9(23.1 \%)$ & $\mathrm{n} / \mathrm{a}$ \\
\hline child & Yearly & $4(1.1 \%)$ & $1(2.3 \%)$ & $\mathrm{n} / \mathrm{a}$ \\
\hline & Rarely & $53(14.7 \%)$ & $12(30.8 \%)$ & $\mathrm{n} / \mathrm{a}$ \\
\hline & Never & $1(.3 \%)$ & $3(7.7 \%)$ & $\mathrm{n} / \mathrm{a}$ \\
\hline \multirow{3}{*}{$\begin{array}{l}\text { Satisfaction with } \\
\text { the disclosure } \\
\text { decision }\end{array}$} & $\begin{array}{l}\text { Very /quite } \\
\text { satisfied }\end{array}$ & $327(90.8 \%)$ & $27(69.2 \%)$ & $95(70.4 \%)$ \\
\hline & $\begin{array}{l}\text { Neither satisfied } \\
\text { nor dissatisfied }\end{array}$ & $27(7.5 \%)$ & $10(25.6 \%)$ & $32(23.7 \%)$ \\
\hline & $\begin{array}{l}\text { Very/quite } \\
\text { dissatisfied }\end{array}$ & $6(1.7 \%)$ & $2(5.2 \%)$ & $8(5.9 \%)$ \\
\hline
\end{tabular}


Figure captions

Figure 1. Themes and subthemes with regards to parents' experiences of talking about autism with their children 